\title{
In Memoriam: John Urry (1946-2016)
}

\author{
Bianca Freire-Medeiros
}

A última vez em que estive pessoalmente com John Urry foi no dia 10 de junho de 2012. Era o domingo que antecedia a abertura das atividades da Rio+20: Conferência das Nações Unidas sobre Desenvolvimento Sustentável. John - ele fazia questão que evitássemos a formalidade dos sobrenomes e títulos - chegara no dia anterior como convidado do Fórum de Ciência, Tecnologia e Inovação. Ele estava muito entusiasmado com a possibilidade de discutir os argumentos que desenvolvera em Climate Change and Society (2011), livro que inaugura o que poderíamos chamar de sua “tetralogia pós-carbono”, composta ainda por Societies Beyond Oil (2013), Offshoring (2014) e What Is the Future? (2016). Nestas que foram suas obras derradeiras, John Urry assume, em definitivo, o papel de intelectual público, comprometido com a crítica ao capitalismo e seus excessos. Esse engajamento contra o neoliberalismo ganhara recentemente uma face institucional a partir da fundação do Institute for Social Future ${ }^{1}$, um think tank voltado para a formulação de propostas comprometidas com "outros futuros" - não apenas possíveis, mas desejáveis - onde Urry atuou até a sua morte, em março deste ano.

John Urry viajou ao Brasil outras três vezes. Em maio de 2000, esteve no Rio de Janeiro como palestrante convidado do seminário internacional "Limites do Imaginário", organizado pela Universidade Candido Mendes em parceria com a Unesco. O evento reuniu "estrelas" do mundo acadêmico, como Fredric Jameson e Susan Buck-Morss, para discutir um tema relativamente novo àquela época: a globalização cultural e seus efeitos. Urry comparecia como o autor dos já clássicos The End of Organized Capitalism (1987, em co-autoria com Scott Lash), The Tourist Gaze (1990) e Consuming Places (1995). Se boa parte da reflexão acumulada até então sobre o capitalismo globalizado erguia-se tendo o tempo do trabalho e os arranjos produtivos como solo empírico, nesses três livros Urry voltava-se precisamente para o tempo do não-trabalho, encontrando em expressões negligenciadas, como o lazer e o turismo, um caminho para decifrar a globalização. Mas, em vez de optar pela reciclagem das ideias testadas e consagradas, Urry fez do evento no Rio um campo de provas para argumentos que seriam desenvolvidos a partir dos anos 2000 e para os quais irá, mais adiante, cunhar o termo "New Mobilities

1 Para os princípios que norteiam o instituto e seus objetivos, ver: http://www.lancaster.ac.uk/ social-futures/wp-content/uploads/2015/o8/ISF-manifesto.pdf 
Paradigm" (PNM no acrônimo em português). Intitulada "Inhabiting the Car", sua comunicação expõe o estranhamento diante do silêncio que as Ciências Sociais reservaram a uma das invenções mais exemplares de uma tecnologia globalizada e definidoras do estilo de vida do Século XX: o automóvel. Nesse sentido, o texto antecipa o debate que veremos detalhado no artigo publicado em parceria com Mimi Sheller ${ }^{3}$ naquele mesmo ano e que será por ele revisitado outro par de vezes ${ }^{4}$ já no contexto do PNM.

Na primavera de 2007, John Urry fez sua segunda viagem ao Brasil. Dessa vez seu destino foi Recife, onde participou como um dos oito conferencistas convidados pelo XIII Congresso Brasileiro de Sociologia. A experiência o marcou duplamente: por um lado, alegrou-se com o enorme prestígio que "O Olhar do Turista”, na tradução publicada pelo SESC em 1999, havia alcançado entre os pares brasileiros 5 ; por outro, o contraste entre a estrutura luxuosa da universidade privada que o recebera anos antes no Rio e a precariedade da Universidade Federal de Pernambuco lhe pareceu "obsceno", para usar o exato adjetivo empregado pelo próprio John. Ex-aluno da tradicionalíssima Universidade de Cambridge, onde cursou a graduação em Economia (1967) e o doutorado em Sociologia (1972), não lhe era de modo algum estranha a ostentação acadêmica. Porém, jamais passou imperceptível a quem conviveu com John a sua aversão aos ambientes e posturas pomposos. Não surpreende, assim, que a estrutura mais democrática de acesso e a horizontalidade das relações de trabalho oferecidas pela Universidade de Lancaster, uma das "novas universidades" públicas fundadas nos anos 1960, o tenham conquistado. A surpresa talvez esteja em saber que justamente aquele que teorizou com tanto afinco as "vidas móveis" tenha passado toda a sua vida profissional na mesma instituição: em 1970, o recém-inaugurado Departamento de Sociologia ofereceu a Urry seu primeiro emprego como professor assistente; 46 anos depois, já consagrado com um dos cinco melhores do Reino Unido, o departamento de sociologia se despediu de seu "Distinguished Professor".

2 Disponível em: http://www.lancaster.ac.uk/fass/resources/sociology-online-papers/papers/ urry-inhabiting-the-car.pdf

3 Sheller, Mimi \& Urry, John. "The city and the car" in: International Journal of Urban and Regional Research, 2000.

4 Especialmente no dossiê "Automobilities", publicado em 2004 no periódico Theory, Culture and Society, e no livro After the Car (2009, em co-autoria com Kingsley Dennis).

5 Obviamente, cabe celebrar que "O Olhar do Turista" seja o principal texto de referência da sociologia do turismo no Brasil, mas não deixa de ser lamentável que siga sendo a única obra de John Urry disponível em português. Foge-me ao entendimento que sequer tenha havido interesse em traduzir a terceira edição, escrita em coautoria com Jonas Larsen, sob o titulo The Tourist Gaze 3.o. 
John Urry voltou ao Rio de Janeiro em setembro de 2011, dessa vez por conta do projeto "Emerging Middle Classes and Low Carbon Mobilities: Setting longterm foundations for transnational research", que havia sido por nós desenhado em 2009, durante minha estadia no Center for Mobilities Research (CeMoRe), o grande núcleo de propagação do PNM que Urry e Mimi Sheller fundaram em 2003 e que, mais adiante, se ramificou em outras redes transnacionais como a PanAmerican Mobilities e a Cosmobilities. O financiamento da British Academy (ao qual se somaram, mais adiante, recursos da Faperj e da CAPES) permitiu que reuníssemos em dois eventos - o primeiro na Universidade de Lancaster (2010) e o seguinte no CPDOC da Fundação Getúlio Vargas - pesquisadores interessados em refletir sobre os modos pelos quais ambientes culturais, institucionais e infraestruturais específicos podem reforçar, reproduzir, ou desestabilizar determinadas tendências de longo prazo nos regimes de mobilidade. Foram três dias intensos durantes os quais a "mobilities gang", como John carinhosamente nos batizou, foi provocada a responder, ou pelo menos se deixar inquietar, por uma indagação: o Brasil, sendo uma economia emergente, teria maior potencial para desenvolver sistemas de mobilidade sustentáveis do que as economias avançadas?

O episódio da Rio+20 marca, portanto, a última "viagem corpórea" - para usarmos sua tipologia - que John Urry fez ao Brasil. Isso não quer dizer, felizmente, que tenhamos visto a derradeira incursão dele entre nós. Enquanto escrevo este pequeno texto, em coro às centenas de vozes que vêm prestando homenagem póstuma a John Urry desde diferentes partes do mundo (ver http://wp.lancs.ac.uk/ john-urry/), mais de cinco mil volumes que compunham seu acervo pessoal estão sendo empacotados pela Universidade de Lancaster na intenção de atravessar o oceano e encontrar pouso na Biblioteca Florestan Fernandes da FFLCH-USP. Fogem-me palavras para expressar o quanto me honra termos sido elegidos para assegurar a mobilidade das ideias de John Urry neste vasto Sul Global. Escolho, assim, encerrar evocando novamente aquele domingo em que dei início a estas notas. Na companhia de um casal de amigos em comum (e também sociólogos, Licia Valladares e Edmond Prétéceille), almoçamos juntos em minha casa e assistimos a uma partida da Eurocopa na televisão. Praticante assíduo do tênis de quadra - com quase 1,90m de altura, sobravam-lhe alcance e precisão - John não era exatamente um aficionado por futebol. Enquanto se desenrolava o jogo, eu tentava não me perder no vai-e-vem de assuntos variados, uma característica marcante das conversas com John. Sou incapaz de retraçar na memória a avenida de temas que percorremos naquela tarde; lembro-me bem, contudo, de ele recomendar com entusiasmo a leitura de Solar, do inglês Ian McEwan, "primeiro romance 
sobre mudança climática", segundo a descrição sucinta e provocativa que ele me ofereceu. Assim que soube de sua morte, adquiri o livro e foi como se tivesse novamente John por companhia. Podia escutar sua risada franca enquanto lia as cômicas desventuras do cientista Michael Beard, o anti-herói misógino, trapaceiro e vaidoso de McEwan. Patologicamente egoísta, incapaz de qualquer sacrifício físico ou moral, Michael Beard encarna os pecados do capitalismo que levaram à crise em que o planeta se encontra. De uma generosidade ímpar, sem qualquer apego às deferências acadêmicas, sempre leal e comprometido com os princípios de um mundo mais justo, John Urry encarnou as virtudes capazes de fazer frente aos pecados de qualquer Michael, Michel ou Donald. Esse enfrentamento é necessário e urgente, dentro e fora da academia, porque os futuros, como John nos ensinou, são campos de disputa no presente e chegam cada vez mais depressa.

Recebido para publicação em: 20/11/2016. Aceito para publicação em: 01/12/2016. 